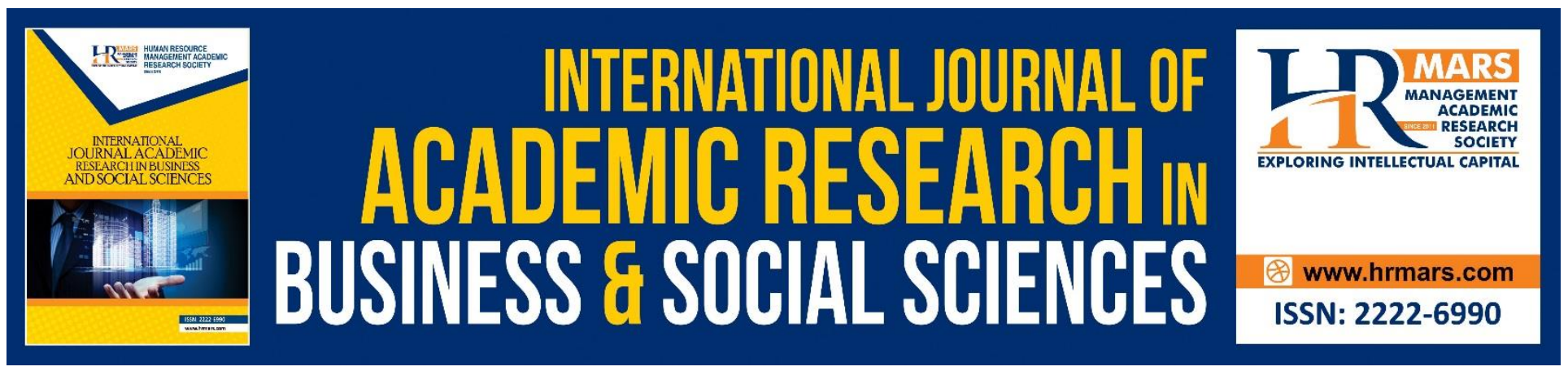

\title{
New Information Management Dimension in Blockchain
}

Fauziah Salleh, Rohaniza Md.Radzi, Norhayati Hussin, Abdul Rahman Ahmad, Zaharuddin Ibrahim

To Link this Article: http://dx.doi.org/10.6007/IJARBSS/v8-i12/5241

DOI: $10.6007 /$ IJARBSS/v8-i12/5241

Received: 14 Nov 2018, Revised: 21 Dec 2018, Accepted: 30 Dec 2018

Published Online: 15 Jan 2018

In-Text Citation: (Salleh, Md.Radzi, Hussin, Ahmad, \& Ibrahim, 2018)

To Cite this Article: Salleh, F., Md.Radzi, R., Hussin, N., Ahmad, A. R., \& Ibrahim, Z. (2018). New Information Management Dimension in Blockchain. International Journal of Academic Research in Business and Social Sciences, 8(12), 1382-1391.

\section{Copyright: (c) 2018 The Author(s)}

Published by Human Resource Management Academic Research Society (www.hrmars.com)

This article is published under the Creative Commons Attribution (CC BY 4.0) license. Anyone may reproduce, distribute, translate and create derivative works of this article (for both commercial and non-commercial purposes), subject to full attribution to the original publication and authors. The full terms of this license may be seen

at: http://creativecommons.org/licences/by/4.0/legalcode

Vol. 8, No. 12, 2018, Pg. 1382 - 1391

http://hrmars.com/index.php/pages/detail/IJARBSS

JOURNAL HOMEPAGE

Full Terms \& Conditions of access and use can be found at http://hrmars.com/index.php/pages/detail/publication-ethics 


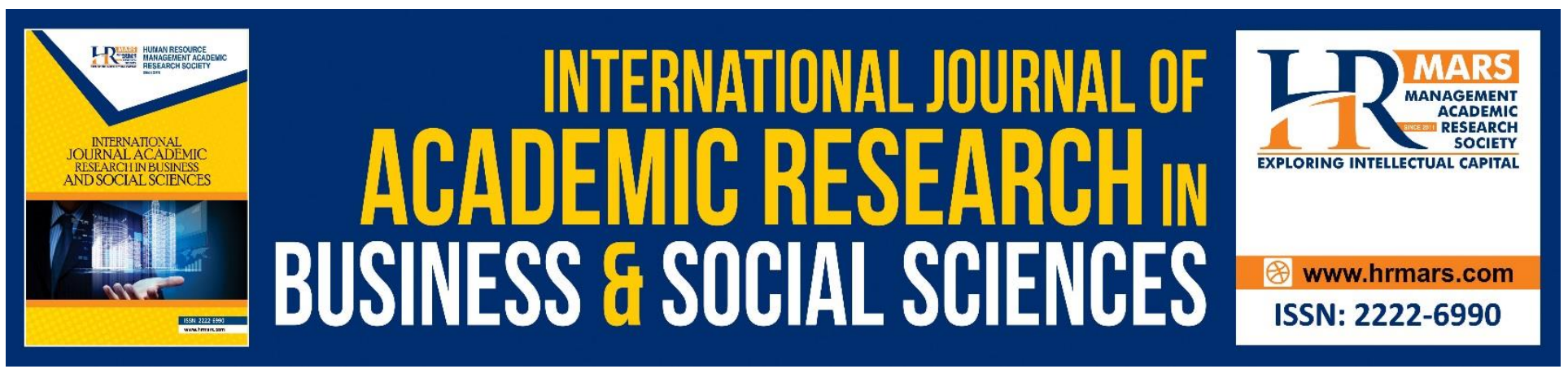

\title{
New Information Management Dimension in Blockchain
}

\author{
Fauziah Salleh, Rohaniza Md.Radzi, Norhayati Hussin, Abdul \\ Rahman Ahmad, Zaharuddin Ibrahim \\ Faculty of Information Management, Universiti Teknologi MARA, UiTM Selangor, Malaysia
}

\begin{abstract}
This is a conceptual paper is to describe the new era of Information Management through block-chain technology. The study reviews literature on block-chain technology focusing on the characteristics, advantages, and achievement of blockchain. The paper goes on to analyze the role and principles of blockchain to Information Management (IM). Conclusions from the literature are drawn that states the impact of blockchain to IM should be taken into consideration. The paper ends with recommendations on future research to investigate the existing loopholes in blockchain technology. Keyword Information Management, Block-chain, Information Management Dimension
\end{abstract}

\section{Introduction to Information Management}

The meaning of Information management is much more than technology. Information management is process includes planning, organizing, structuring, processing, controlling, evaluating and reporting that support the creation and implementation of information. There are few elements in Information Management include information itself (structure of information or information architecture, quality of content) and the involvement of people, process and technology. To have a good planning and strategic in information management each of these elements must be thoroughly addressed. The goal of information management is to help people to access, process and use information efficiently and effectively. Information Management will help organization to operate more competitively and strategically and help people achieve better accomplish in their tasks and become better informed. A good information management framework is when organization can manage the full lifecycle of information ranging from the information creation until the use of information. Any data or information that is stored will be adequately protected against unauthorized access, as security, privacy and copyright concerns exist. The management of information processes is seen as a strategic mileage that affords four kinds of benefits to an organization: A reduction of costs; A reduction of uncertainty or risks; Added value to existing products and services; And the creation of new value through the introduction of new information-based products and services. One of the technology 
INTERNATIONAL JOURNAL OF ACADEMIC RESEARCH IN BUSINESS AND SOCIAL SCIENCES

Vol. 8, No. 12, Dec, 2018, E-ISSN: 2222-6990 @ 2018 HRMARS

uses to manage data with high security concern that we would like to discuss here is Blockchain Technology.

\section{Block-chain Technology}

Blockchain technology could simplify the management of trusted information, making it easier for government agencies to access and use critical public-sector data while maintaining the security of this information. A blockchain is using decentralized and distributed of ledger for verifying and recording of transaction. The technology will allow sending, receiving and recording of transaction between different people. The database or records of the transaction are group together into block of information. The chains that are added to each block are sharing across a network of computers through peer to peer network. The blocks are linked together using cryptography technique. This has made the records added to the chain are difficult to change by the unauthorized users. To ensure all the copies of the database are the same, the network will constantly check and verify the records using automation and shared governance protocols. (Bruyn, 2017)

Blockchain is described by Stuart Haber and W.Scoot Stornetta in year 1991 and in year 2008, Satoshi Nakamoto was the first invented blockchain to serve as the public transaction ledger of the cryptocurrency bitcoin. This discovery has made blockchain as the first digital currency that able to solve the double-spending problem without the need of a trusted authority or central server. Blockchain technology is able to stop the use of middle person in exchange of money via online database and recording the transaction, establishing identity and contracts. Blockchains have been used to strengthen cyber-currencies like bitcoin, and soon many other applications are possible to uses such technology.

\section{Characteristics of Blockchain}

Blockchain has changed the way we do business. The characteristics of blockchain is giving new transformative over the information exchange on the website. In industry where data sensitivity is crucial, such as financial, government and healthcare, blockchain can become one of the solutions. The below is four characteristics that makes blockchain different that other technology: (Zheng, Xie, Chen, \& Wang, 2017)

(i) Decentralization: Blockchain has decentralized the trust and enable the flow of information without the use of middle interaction. Each member within the business network will keep verify and clear the financial transaction without the need of other trusted person existence. This will remove the intermediary cost and complexity of transaction process flow.

(ii) Persistency: Due to all transactions that are sending over the network requires the verification and recording in each block, it is impossible for any interruption during the transaction. Furthermore, each block will be verified by others node and transaction will be checked and confirmed. The fabrication of information will be detected easily.

(iii) Anonymity: The blockchain network users can interact with each other using the generated address. Each time block is sending from one node to another node, addresses are generated to avoid the exposure of personal identity. There are no more 
centre party that will keep the information. Even though this mechanism able to keep privacy on certain transaction but it will not able to guarantee the perfect privacy.

(iv) Audibility: When timestamp is used in each business transaction for verification and recording activity, users are able to confirm and detect previous record before it will go through any node within the broadcast network. The transaction can be traced to previous transactions iteratively. It improves the traceability and the transparency of the data stored in the blockchain.

\section{Advantages of Blockchain}

Blockchain characteristics have giving so many advantages to the application which used the technology. The followings are some of the advantages of blockchain technology: (Adam-Kalfon \& El Moutaouakil, 2017)

(i) Greater transparency: The uses of blockchain technology will make the transaction history more transparent. Blockchain is the type of distributed ledger that allows network members share the same documentation. The shared version is updated after receiving the approval from everybody on the same network. Any changed make, will require changes in all succeeding records and agreement of the entire network. Thus, data on a blockchain is more accurate, consistent and transparent than when it is pushed through paper-heavy processes. It is also available to all participants who have permissioned access.

(ii) Enhanced security: Before each transaction is recorded, permission is granted for all transactions. After getting approval to perform the transaction, records is encrypted and linked to the previous transaction. The information will not store in a singgle server but will be stored in all computers across the network. Hackers will be difficult to compromise with the transactions. This characteristic in blockchain technology will prevent from fraud and unauthorized activity.

(iii) Improved traceability: Blockchain design format enable to trace any problem or issue rise during the transaction and will make the correction (if any). It also creates an irreversible audit trail. The audit trail will shows the originality of the asset and where it comes from. This historical transaction data can help to verify the authenticity of assets and prevent fraud.

(iv) Increased efficiency and speed: The traditional process of financial transaction is a time-consuming that is open to human error and often requires third-party mediation. Blockchain technology will streamline the transactions and can be completed faster and more efficiently. Correction or updating of information can be done at one single ledger that share among the participant and with less confusion. And when everyone has access to the same information, it becomes easier to trust each other without the need for several mediators. Thus, clearing and settlement can occur much quicker.

(v) Reduced costs: Blockchain can reduce cost of transaction that appears because of the existence of many intermediaries person. The most important thing is we need to trust the data within the blockchain technology. We also do not need to check many 
INTERNATIONAL JOURNAL OF ACADEMIC RESEARCH IN BUSINESS AND SOCIAL SCIENCES

Vol. 8, No. 12, Dec, 2018, E-ISSN: 2222-6990 @ 2018 HRMARS

documents because every person in the network has given access to the original version that is immutable version.

\section{Achievement of Blockchain \\ Worldwide Achievement}

The elimination of third-party intermediaries through decentralisation across the network not only enables a more efficient digital ecosystem in this fast-paced globalised world through speedier and lower cost execution of transactions but also reduces the security risks which arise due to the existence of a central point of failure under the conventional manner of centralised system (Zakaria, Kunhibava, \& Munir, 2018). There are exciting opportunities in various sectors that blockchain holds for its decentralisation feature such as:

- $\quad$ Financial Services: Blockchain technology enables the creation of a peer-to-peer economy in which cheaper cross-border remittances can be made due to the elimination of intermediaries and lower processing fees payable. For example, global enterprise software firm R3 has created Corda which is a blockchain based digital ledger platform for the recording, management and synchronisation of financial agreements between regulated financial institutions.

- $\quad$ Commerce: Blockchain technology enables the creation of a decentralized marketplace for the trading of goods which would make electronic commerce trading platforms more attractive to businesses such as Small Medium Enterprises ('SME') due to lower transaction costs in the absence of any intermediary.

- Government Services: Blockchain technology enables the creation of a more transparent and accountable governance system. In addition, the use of blockchain may also bring about processing efficiencies as exemplified by Estonia's e-government system which enables almost instant tax filing and vote casting.

Blockchain technology, as well as related innovations, will affect the economy, banking and financial Landscape; especially on applications related to identity management, smart contracts, supply chain domination and authentication of both real and digital assets involving intellectual property rights (Nazri, 2017). Companies can operate at lower costs, reduce accounting fraud, and audit and guarantee services become irrelevant. Blockchain data integrity will contribute to overall systemic risk reduction and operational improvements. Therefore, it is important for all firms to begin integrating Blockchain technology into their company (Pitis Writer, 2018).

\section{Dubai}

Dubai emerged as a developing country Blockchain and planned to save 25 million working hours annually through paperless transactions by transferring all transactions to Blockchain management (Wartawan Sinar Harian, 2017). Even the Dubai Land Department has become the first government entity in the world to fully adopt Blockchain management. It records all property contracts, including rental listings and links them to the Electricity and Water Authority of Dubai, telecommunication systems and various property-related bills. The UAE financial centre regulator practices financial or fintech technology, providing an environment to start-up companies undergo trial and error, which 
is one of the first such programs in the region. With this, it is evident that Blockchain's technology is most appropriate for a developing economy where most of the rules are still growing and have not yet been set. This enables them to make blockchain technology a foundation for all initiatives, saving money and improving efficiency and development.

\section{Seoul}

Seoul Park Mayor Won-soon has introduced a five-year plan to develop blockchain in the City and intends to make the city a "Block Network Industry Ecosystem Center". The project called "The Blockchain City of Seoul" contains several steps to promote and develop initiatives and education related block networks in the city from 2018-2022. By 2022, Seoul plans to set up a 100 billion-publicprivate fund (\$88.2 million) to invest in "startup blockchain" in Seoul. The fund will earn 13.6 billion Won (\$11.9 million) from the city government. Additionally, city authorities plan to spend 60.3 billion Won ( $\$ 53.1$ ) to create two business centres to house 200 block network firms by 2021 to handle two centralized education aimed at training 730 industry experts over the next five years. At the same time, the authorities plan to launch 14 block-based powerful systems, including voting systems, charity management, and vehicle history reports. "Distributed Ledger Technology" (DLT) based on the "Core Technology Revolution of the Fourth Industrial" will be the basis of IT's future (Pitis Writer, 2018).

\section{BlackBery}

As part of its interest in security and computing, the software company and former BlackBerry smartphone manufacturer have released a platform powered by a blockchain. This new product focuses on healthcare areas where BlackBerry has partnered with ONEBIO technology firm to develop an "ultra-secure" ecosystem supported by blockchain. The system is designed to store medical data, where information can be included by the patient's biometric device, laboratory, and Article Internet (IoT). Once entered, the data will be anonymous and shared with the investigator. Recent blockchain initiatives indicate the company's move to other areas besides the global smartphone market. (Pitis Writer, 2018)

\section{Malaysia Achievement}

Malaysia has always encouraged the blend of technological innovation into the business operation. In March 2017, Malaysia's International Trade and Industry Minister was urging the local SMEs to adopt the usage of electronic trading platforms as it is almost compulsory for every business to be part of it. In line with the government's aspiration, the incorporation of blockchain technology in electronic trading platforms would be attractive to SMEs as the need for middlemen intermediaries could be eliminated and this, in turn reduces the transaction costs of running businesses.

Apart from leveraging on the efficiency benefits that the blockchain technology brings, the usage of blockchain technology may be the solution to Malaysia's cyber security quandaries and alleviate the vulnerability of Malaysian organisations, public or private, to being victims of cyber-attacks. During the Round Table Discussion Securing Critical Systems for The Protection of National Digital Assets held in June 2016, chief executive of Cyber Security Malaysia was quoted as saying that a worrying 
$65 \%$ of organisations in Malaysia are at risk of being victims of cyber-attacks and that 'government sectors are the most vulnerable targets, followed by the telecommunications and financial sectors'. In this connection, it should be noted that Malaysia is ranked as the tenth most likely country in the world to be attacked by mobile malware in a report titled 'IT Threat Evolution' issued in 2016 by Kaspersky Lab. Blockchain technology may offer a saving grace to the cyber security thread in the local scene as the decentralised feature of the technology brings with it certain security benefits.

The Malaysia Economic Monitor ('MEM') which was launched in June 2017 is to provide quality and effective data management so as to enable more informed policy-making and better public service delivery. With more data available to the public, they will be able to create new businesses'. The results will improve the data storage and processing capabilities that brought by blockchain technology and would in turn lead to wider public access to data in line with the government's policy of increasing data availability to the public. Additionally, the immutable nature of blockchains would also be of great utility in relation to the establishment of an intellectual property payment system as royalties can be imposed based on the degree and extent of reproduction and usage as recorded in the ledger records.

The private sector can also take the lead in taking advantage of the immutability nature of blockchain. For instance, under Malaysian company law, shareholders who are entitled to vote must be physically present at any general meeting in order to exercise their right to vote. Alternatively, shareholders who are entitled to vote may appoint a proxy to exercise their right to vote on their behalf. Although the recently enacted Companies Act 2016 has made it easier for proxies to be appointed, this does not detract from the requirement of physical presence, whether by the shareholders themselves or their proxies, in order for the former to exercise its right to vote. In addition, in the Malaysian Code on Corporate Governance 2017, the Malaysian Securities Commission ('SC') encourages electronic voting as it promotes shareholder participation in general meetings as it does away with the need for shareholders to be physically present at the general meeting in order to vote. Given that the SC is proposing to embrace electronic voting moving forward, the immutable nature of blockchain ledger records would render blockchain to be the technology of choice for the development of an electronic voting system to be used by Malaysian companies.

\section{Role of Blockchain in IM}

The Principle of Blockchain that related to IM

The followings are few principles of blockchain (Chandrayan, 2018):

Decentralization: Blockchain is a P2P network where no single participant (user) controls the transaction, the power is distributed among all the participants in this network, that means no single stakeholder can hack, manipulate or close the chain of blocks or can shut it down. This blockchain network due to its distributed (Decentralized) mechanism is free from any hacks or fraud.

Integrity: In the blockchain powered network all the participants have got the rights to make decisions, here the trust in the system is not forced but is totally guided by user intuition. The tight integrity is observed in the way every user gets incentivized for their effort and also in the way this entire P2P network function. 
INTERNATIONAL JOURNAL OF ACADEMIC RESEARCH IN BUSINESS AND SOCIAL SCIENCES Vol. 8, No. 12, Dec, 2018, E-ISSN: 2222-6990 @ 2018 HRMARS

"For the first time ever, we have a platform that ensures trust in transactions, and...recorded information no matter how the other party acts." - Tapscott

Cryptography: Fair To All - Blockchain has been designed with this core principle to provide high level of security and authenticity to the user. To ensure tightly knit security \& data integrity it uses the power of cryptography. The Blockchain transaction mechanism is favourable \& rewarding for an authentic user at the same time it is very harsh on the reckless user. That means the blockchain system is fair for all who behave as a good user and reward them appropriately. But if you go about using it with wrong intent you are not spared and penalized.

Security: Blockchain being distributed network, there is no one central point of failure and also no single person can behave recklessly to damage the entire chain of the network. The damage because of any individual hack of the password will limit to that single person itself. With blockchain PKI (Public Key Infrastructure) encryption mechanism your transaction over the network is highly secured. So, largely you can trust Blockchain technology to ensure your transactions gets completed without being hacked.

Inclusive: The Blockchain is inclusive in its approach where everyone is independent to participate without any discrimination in the global economy. The bitcoin allows all the richest, the poorest, to invest in their capacity and become part of this global economy, as the need to have a bank account was totally removed. They can directly decide to transact to whomsoever they want without thirdparty intervention that to paying zero to a very little transaction fee.

Blockchain Respects Your Privacy: In a digital world, where consumers and businesses transact online for shopping, transferring payments $\&$ to verify information for a myriad of purposes, ensuring data privacy has become paramount. Its Strong Hash Key encryption is quite secure and helps you exchange data over the internet without disclosing your true identity. With Blockchain your identity is never revealed while you transact using the blockchain P2P network. Your Rights and freedom are clear and enforceable, as you become part of the blockchain ecosystem.

\section{Impact of Blockchain to IM}

Blockchain allows digital information to be stored as the same information block across its network and recorded in digital ledgers. This is a database specially designed to be constantly updated and applied directly by each participating user in confirming the transaction separately. Since it can be programmed to record almost all values, Blockchain becomes a new type of internet that provides all kinds of solutions except for financial or fintech technology.

Blockchain's functions and interests within the data and information chain are (Wartawan Sinar Harian, 2017): Supply chain auditing: Providing easy ways for company and product verification.

Governance: Enables full transparency for voting or polling.

File storage: Data and information distributed across the entire network protects files from being hacked or lost.

Public funding or crowd funding allows people to express their opinions directly in product development and development. 
INTERNATIONAL JOURNAL OF ACADEMIC RESEARCH IN BUSINESS AND SOCIAL SCIENCES

Vol. 8, No. 12, Dec, 2018, E-ISSN: 2222-6990 @ 2018 HRMARS

IP protection and distribution: Allows artists to sell their creations directly to audiences and automatically submit royalties to all creators with the help of smart contracts.

eCommerce: Eliminates middleman, confirms identity, abolishes fees \& restrictions and follows transactions from the sale to delivery basis.

Security: Through data storage across its network, Blockchain eliminates the risks that come with centrally stored data.

Advertising: Customers will be given digital coins when viewing items online, for each click and more digital coins value when making a purchase.

\section{Conclusion Finding}

Blockchain technology can potentially be used to enhance the levels of systemic security as compared to conventional technology given the application of up-to-date asymmetrical encryption methods referred to as 'public' and 'private' keys. Below are the sets out how the high degree of security in blockchain can deliver better protection to various parties, particularly consumers;

Digital Assets Ownership and Trading - Blockchain technology may bring about a paradigm shift with regard to the manner in which digital assets are traded and held. In particular, the cryptographic security provided by the technology would significantly enhance the degree of protection afforded to digital assets transactions

Proof of Identity - Blockchain technology may prove to be a panacea for issues relating to identity management in an increasingly digitised global economy as the cryptographic security under blockchain technology would significantly enhance the degree of protection afforded to any transfer and storage of personal and sensitive information. Blockchain may prove to be an invaluable tool in the area of identity authentication in general and Know Your Customer in particular.

Internet of Things ('IoT') - Blockchain technology enables the idea of loT to come closer to becoming a reality by providing a mechanism to track the data of individual devices. These data can then be used to enable interoperability between various devices and the data exchanged under such interoperations can in turn be recorded in a data exchange ledger.

The Security Intelligence Report ('SIR'), Vol 21, which was released by Microsoft in December 2016 listed Malaysia as the 11th most vulnerable nation in the Asia Pacific Region in terms of exposure to cybercrimes. One of the most common cybercrimes in Malaysia is that of phishing scams. According to data collated by the Royal Malaysian Police, a total of RM1.9m was lost due to such scams in 2016 alone. The submission of information by customers during the Know Your Customer ('KYC') process to financial service providers in Malaysia normally become the target of phishing attacks due to the Malaysian context-sensitive nature of the information which would enable the phishers to have access to the financial assets of its owner. As such, blockchain technology may be the answer to the information transfer conundrum. As blockchain technology enables the storage and transfer of personal and sensitive information in cryptographically secured data packets, this would mitigate the potential implications to phishing victims.

\section{Limitation and suggestion for further study}

The risky ventures discussed above show how the unique attributes of blockchain technology have been exploited. In all the cases discussed cryptocurrencies have been used to facilitate vice activities. 
There are a few countries in the world that have actually banned cryptocurrencies, for example: Bangladesh, Bolivia, Ecuador, and Kyrgyzstan. In Malaysia, bitcoin is not recognised as legal tender, at the same time it has not been expressly made illegal. Currently, BNM is studying cryptocurrencies. As a start, BNM has announced that from 2018 onwards, all parties acting as exchanges in digital currency would be deemed as 'reporting institutions' under the Anti-Money Laundering, AntiTerrorism Financing and Proceeds of Unlawful Activities Act 2001. This means that businesses that are involved in converting crypt currencies to fiat money would be required to provide detailed information on buyers and sellers of such currencies.

Recently, at the Money Services Business Asia Pacific Conference, BNM stated that bitcoins have a lot of advantages; however there are abuses too in its use. Thus, good regulation and enforcement are necessary. Blockchain technology use can be applied to more than just money, all types of the transaction involving information, goods, assets and property can benefit from its use. Further research is required to investigate the existing loopholes, only then can amendments be recommended.

\section{REFERENCE}

Adam-Kalfon, P., \& El Moutaouakil, S. (2017). A Catalyst for New Approaches in Insurance. Power Water House Coopers.

Bruyn, A. S. (2017). Blockchain - An introduction. University Amsterdam, 1-43. https://doi.org/10.13343/j.cnki.wsxb.2012.09.008

Chandrayan, P. (2018). BlockChain Principle, Type and Application and Why You Should Care About It. Retrieved October 21, 2018, from https://medium.com/swlh/blockchain-principle-typeapplication-why-you-should-care-about-it-8c8a39113c7d

Nazri, I. (2017). BlokTex 2017: Kenali Teknologi Blockchain - Amanz. Retrieved October 21, 2018, from https://amanz.my/2017134929/

Pitis Writer. (2018). The Future is Now. Retrieved October 21, 2018, from https://blog.pitiscoin.asia/

Wartawan Sinar Harian. (2017). Teknologi Blockchain dan kesannya terhadap perdagangan. Sinar Harian. Retrieved from http://www.sinarharian.com.my/bisnes/teknologi-blockchain-dankesannya-terhadap-perdagangan-1.766620

Zakaria, N. H., Kunhibava, D. S., \& Munir, P. A. B. (2018). Prospects and Challenges : Blockchain Space in Malaysia. Malaya University, 3, 1-15.

Zheng, Z., Xie, S., Chen, X., \& Wang, H. (2017). Blockchain Challenges and Opportunities: A Survey. Inderscience Enterprises Ltd., 1-25. 